\title{
Development and Optimization of a Catalytic Thruster for Hydrogen Peroxide Decomposition
}

\author{
Fernanda Francisca Maia', Leonardo Henrique Gouvea1, Luis Gustavo Ferroni Pereira1, \\ Ricardo Vieira ${ }^{1}$, Fernando de Souza Costa ${ }^{1}$
}

\begin{abstract}
Hydrogen peroxide is a non toxic, low cost, green monopropellant with a significant potential for applications in satellite microthrusters. It presents a density-specific impulse similar to hydrazine. A new bulk mixed oxide catalyst for decomposition of hydrogen peroxide has been developed and tested in a $2 \mathrm{~N}$ thruster with modular parts, allowing the use of catalytic beds with different diameters and lengths. A method of experiment design with a star configuration was implemented to optimize the catalytic bed geometry, in order to yield complete peroxide decomposition, reduce thruster size and volume and provide maximum thrust.
\end{abstract}

KEYWORDS: Satellite propulsion, Hydrogen peroxide, Mixed oxide catalyst, Catalytic bed optimization.

\section{INTRODUCTION}

Nowadays, most satellites in Earth orbit utilize hydrazine catalytic decomposition within their propulsion systems. Hydrazine $\left(\mathrm{N}_{2} \mathrm{H}_{4}\right)$ is an expensive and highly toxic (carcinogenic) monopropellant. In the last decade, due to growing concerns about the environment, there has been a significant interest for storable and nontoxic liquid propellants. Hydrogen peroxide $\left(\mathrm{H}_{2} \mathrm{O}_{2}\right)$ is one of the most important candidates for application as a non-toxic, low cost, green-propellant in satellite propulsion systems (Wernimont, 2009).

The traditional catalyst used for $\mathrm{H}_{2} \mathrm{O}_{2}$ decomposition is made of superposed silver gauzes which form the catalytic bed. The use of solutions with high concentration of $\mathrm{H}_{2} \mathrm{O}_{2}$ leads to the increase of the adiabatic decomposition temperature of the monopropellant $\left(632^{\circ} \mathrm{C}\right.$ for $85 \% ; 755^{\circ} \mathrm{C}$ for $90 \% ; 953^{\circ} \mathrm{C}$ for $98 \%$ in mass), making not viable the application of pure silver or silver coated catalysts in long duration operations. The melting point of silver $\left(962^{\circ} \mathrm{C}\right)$ is very close to the decomposition temperature of $\mathrm{H}_{2} \mathrm{O}_{2}$ and, besides, the formation of silver oxide does not allow the extended use of this type of catalyst (Kappenstein et al., 2002). However, it is notorious that the $\mathrm{H}_{2} \mathrm{O}_{2}$ purity level, meaning the amount of stabilizers present in the monopropellant, has high influence in the efficiency of the catalytic system.

The reaction of $\mathrm{H}_{2} \mathrm{O}_{2}$ decomposition for propulsion applications is very fast, where the induction velocity is very dependent on the active sites exposed to the reaction. Since this

三 1.Instituto Nacional de Pesquisas Espaciais - São José dos Campos/SP - Brazil

三 Author for correspondence: Fernando de Souza Costa | Laboratório Associado de Combustão e Propulsão - INPE | Rodovia Presidente Dutra, Km 40 | CEP $12.630-000$ Cachoeira Paulista/SP - Brazil | Email: fernando@Icp.inpe.br

Received: 10/21/2013 | Accepted: 12/30/2013 
reaction is extremely exothermic, a few miliseconds after the contact of the monopropellant with the catalyst, the catalytic bed reaches a temperature high enough to make the reaction almost entirely of thermal nature instead of catalytic.

A large number of transition metal oxides are catalytically active for $\mathrm{H}_{2} \mathrm{O}_{2}$ decomposition (Goldstein, 1974). Nevertheless, a catalyst frequently considered for $\mathrm{H}_{2} \mathrm{O}_{2}$ decomposition, is $\mathrm{MnO}_{2}$. However if there is oxidation of this oxide, it will change to $\mathrm{Mn}_{2} \mathrm{O}_{3}$, that presents a low catalytic activity. On the other hand, higher temperatures lead to the formation of $\mathrm{Mn}_{3} \mathrm{O}_{4}$, which is as active as $\mathrm{MnO}_{2}$ (Hasan et al., 1999).

Rusek (1996) proposed manganese oxides, supported on alumina and silica, to replace the traditional silver catalysts. The results obtained suggest that the catalytic properties of manganese oxides are influenced by the type of support, hence the interest in new, supported catalyst, containing high concentration of surface active species, which can be stable under reaction conditions, typical of space propulsive applications.

Mixed oxides, containing cations of transition metals, are frequently used as bulk catalysts in different reactions. These oxides are generally prepared by thermal decomposition of different precursors, such as hydroxides, carbonates, nitrates and oxalates (Vaccari, 1998).

Taking into account these considerations and the results of preliminary tests, bulk catalysts were developed. Extrudates of cobalt/manganese based mixed oxides were prepared for $\mathrm{H}_{2} \mathrm{O}_{2}$ decomposition, employed in satellite microthrusters. The materials were tested in a modular $2 \mathrm{~N}$ microthruster, specially designed and built with catalytic beds of variable sizes (diameter and length), for catalytic decomposition of stabilized $\mathrm{H}_{2} \mathrm{O}_{2}$, concentrated to $90 \%$ in mass.

A method of experiment design, using a star configuration, was employed to optimize the catalytic bed dimensions, aiming to obtain complete decomposition of propellant, the reduction of thruster volume and mass, and to yield maximum thrust. The modeling of the process was made by the response surface method, adjusting quadratic models to the experimental results, obtained from a factorial planning. Through this modeling, the response sensitivity to the variables can be estimated, besides determining the levels where the response is optimal. The interest factors studied were diameter and length of the catalytic bed, and the response of interest was the thrust generated by the system.

\section{EXPERIMENTAL METHODOLOGY}

\section{HYDROGEN PEROXIDE CONCENTRATION}

Stabilized $50 \% \mathrm{H}_{2} \mathrm{O}_{2}$, supplied by Solvay Chemicals, was concentrated to $90 \%$, in mass, by a counter flow of hot dry air. A deionization treatment may be done before concentration, in order to remove the stabilizers present in the peroxide. Stabilizers can reduce catalytic stability, however, in this work, stabilized peroxide has been used to evaluate the new catalyst.

\section{CATALYST PREPARATION}

Extruded material was prepared from a bulk catalyst, based on manganese and cobalt oxides, capable to spontaneously decompose cold $\mathrm{H}_{2} \mathrm{O}_{2}$. The catalyst was prepared by co-precipitation of solutions of cobalt, manganese and aluminum nitrates (Sigma-Aldrich) in a $\mathrm{Na}_{2} \mathrm{CO}_{3}$ solution at room temperature, keeping a constant $\mathrm{pH}$ of 10 , by addition of a $\mathrm{NaOH}$ solution. A mole ratio of 4:1:1 (Co:Mn:Al) was used. The product of this reaction was filtered, washed, dried and macerated. The powder was then peptized with $\mathrm{HNO}_{3}$ solution and finally extruded, followed by stove drying and calcinations at $900^{\circ} \mathrm{C}$ temperature. The final product presented a cylindrical form with approximate dimensions of $2 \mathrm{~mm}$ diameter and $3 \mathrm{~mm}$ length.

\section{MICROTHRUSTER}

Performance parameters of the new mixed oxide bulk catalyst for $\mathrm{H}_{2} \mathrm{O}_{2}$ decomposition were obtained by tests with a $2 \mathrm{~N}$ thruster, manufactured with modules, including different chambers, nozzles and ring adapters built with 316 stainless steel (Fig.1). To vary the dimensions of the catalytic bed, three chamber modules were designed and manufactured, besides two nozzles and several rings of different lengths and thicknesses, to hold the catalytic beds in place.

The NASA CEA rocket performance code (McBride \& Gordon, 1996) was used to calculate the thruster theoretical performance. Chamber pressure was chosen as $5 \mathrm{bar}$, and the nozzle expansion ratio was calculated as 1.45 , to adapt the nozzle at $600 \mathrm{~m}$ altitude, where the tests were performed. Assuming frozen flow, with $90 \% \mathrm{H}_{2} \mathrm{O}_{2}$, the calculated specific impulse was $1040 \mathrm{~m} / \mathrm{s}$, theoretical characteristic velocity was $940 \mathrm{~m} / \mathrm{s}$ and ideal thrust coefficient was 1.106. Figure 2 shows a computer view of thruster and thrust balance. Pressure transducers and thermocouples were placed before and after injection and after the catalytic bed, as can be seen in Fig. 3. Thrust was measured by a $5 \mathrm{~N}$ load cell. A graphical user interface, written with LabView software, was used to monitor and control the tests. 


\section{TESTS}

Before tests, the mass flow rate of propellant, as a function of differential pressure in the feeding line, was determined to estimate the peroxide tank pressure required to provide the desired mass flow rate during each test. After this procedure, the microthruster was assembled and mounted on the thrust balance, the load cell HBM 1-PW4C3/500G-1 (error $\pm 0.1 \mathrm{~g}$ ) was calibrated using known weights and, finally, continuous and pulsed test firings were performed.

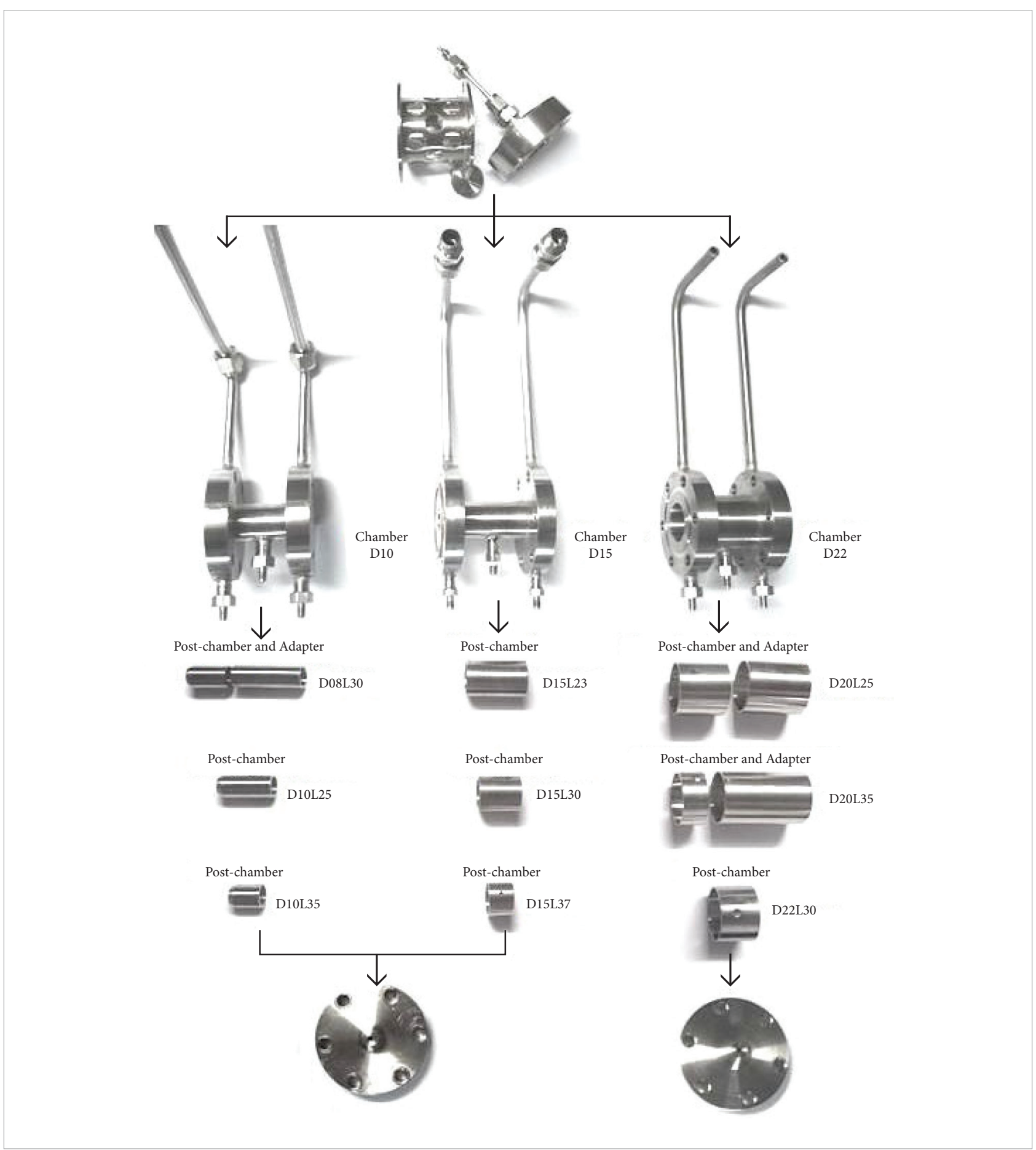

Figure 1. Photography of disassembled thruster parts. 


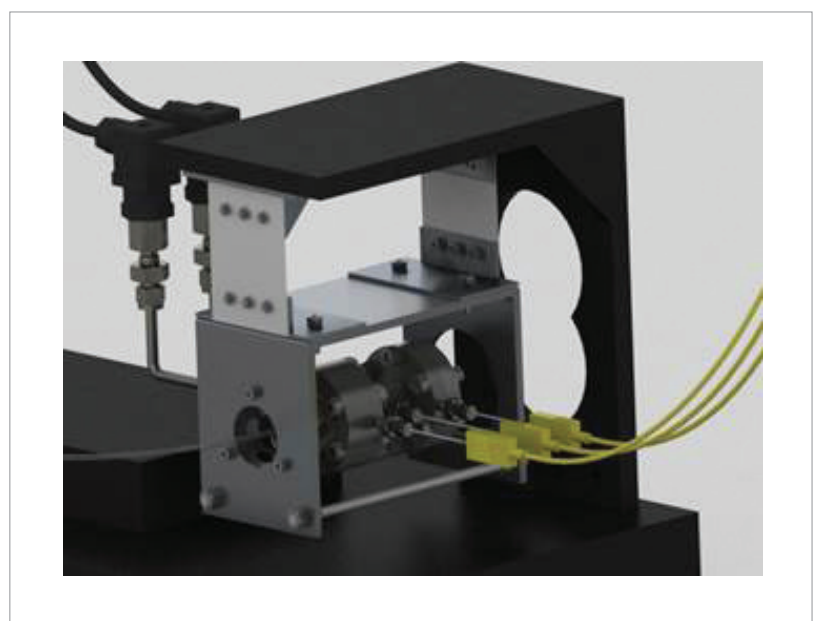

Figure 2. Computer view of thruster and thrust balance.

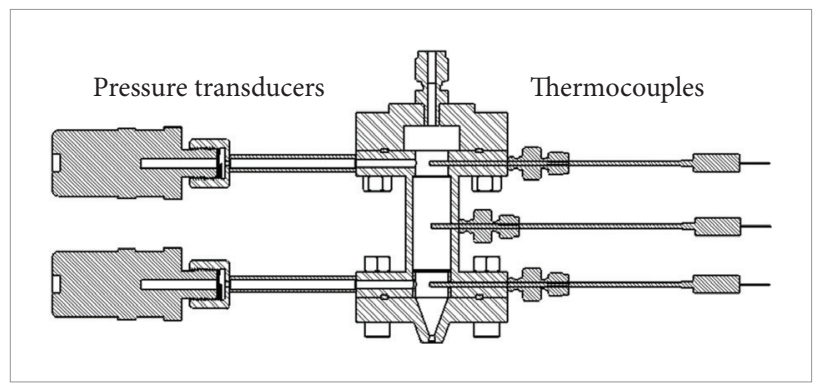

Figure 3. Cut view of thruster with thermocouples and pressure transducers.

\section{RESULTS AND DISCUSSION}

The mixed oxides bulk catalysts prepared in this work had high mechanical strength and low specific area $\left(\sim 6 \mathrm{~m}^{2} / \mathrm{g}\right)$ due to the high temperatures in which they were calcined. Nevertheless, they showed no significant mass loss during tests in the microthruster.

The plan of experiments followed the methodology described by Barros-Neto et al. (1995). Table 1 presents the plan of experiments with a star configuration built from the factorial planning $2^{3}$ ( 2 factors and 3 study levels), added to three replicates at the central point, totalling 11 tests.

A quadratic model was obtained using a factorial design, describing the influences of catalytic bed length $(L)$ and catalytic bed diameter $(D)$ on thrust $(F)$ :

$$
F=2.22+0.084 L+0.247 D-0.344 L^{2}+0.0925 L D-0.573 D^{2}
$$

Table 1. Plan of experiments.

\begin{tabular}{|c|c|c|c|c|c|}
\hline Test & Var 1 & Var 2 & $L(\mathbf{m m})$ & $D(\mathbf{m m})$ & $F(\mathbf{N})$ \\
\hline 1 & -1.00 & -1.00 & 25 & 10 & 1.03 \\
\hline 2 & 1.00 & -1.00 & 35 & 10 & 1.06 \\
\hline 3 & -1.00 & 1.00 & 25 & 20 & 1.21 \\
\hline 4 & 1.00 & 1.00 & 35 & 20 & 1.61 \\
\hline 5 & 0.00 & 0.00 & 30 & 15 & 2.33 \\
\hline 6 & 0.00 & 0.00 & 30 & 15 & 2.14 \\
\hline 7 & 0.00 & 0.00 & 30 & 15 & 2.24 \\
\hline 8 & -1.41 & 0.00 & 23 & 15 & 1.52 \\
\hline 9 & 1.41 & 0.00 & 37 & 15 & 1.69 \\
\hline 10 & 0.00 & -1.41 & 30 & 8 & 0.71 \\
\hline 11 & 0.00 & 1.41 & 30 & 22 & 1.59 \\
\hline
\end{tabular}

$L=$ catalytic bed length; $D=$ catalytic bed diameter; $F$ = thrust.

From this model, the influences of the variables in the test conditions were represented by level lines of the response surface, as depicted in Fig. 4. The responses are indicated on $z$-axis (thrust), with a color bar, as function of the independent variables indicated in the $x$ (diameter) and $y$ (length) axes. Table 2 shows the regression analysis to fit the response function to experimental data.

As seen on Table 2, $L$ and $L D$ present lower coefficients than $D$, indicating that bed diameter presents a more significant influence than bed length in this experiment. The analysis of variance, depicted on Table 3, demonstrates that the model is significant,

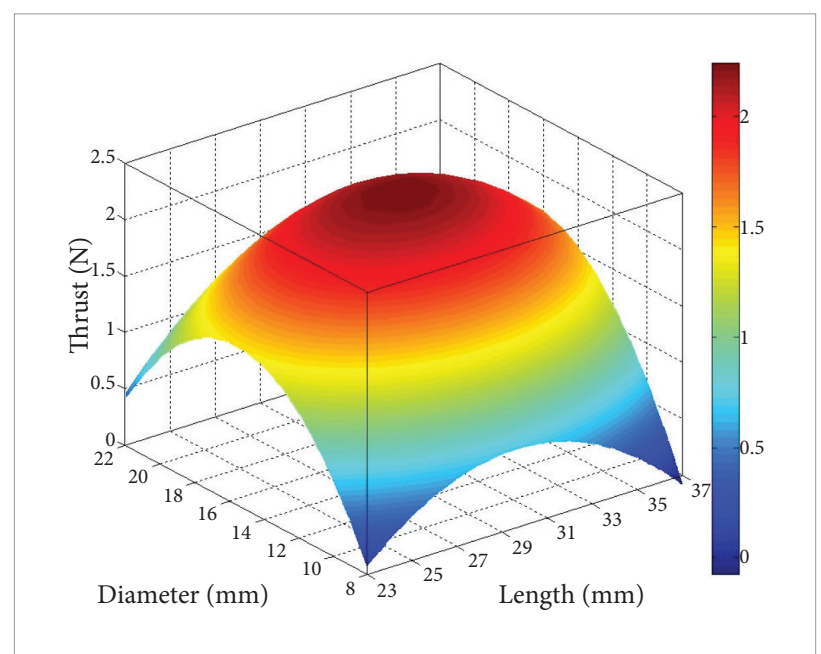

Figure 4. Contour graphic for the variable response studied: thrust $F(\mathrm{~N})$. 
Table 2. Regression analysis using a $2^{3}$ full factorial central composite design.

\begin{tabular}{|c|c|c|c|c|}
\hline Predictor & Coefficient & $\begin{array}{c}\text { Standard } \\
\text { error } \\
\text { coefficient }\end{array}$ & t-value & p-value \\
\hline Constant & 2.2172 & 0.0815 & 27.19 & 0.000 \\
\hline$L$ & 0.0839 & 0.0500 & 1.68 & 0.154 \\
\hline$D$ & 0.2471 & 0.0500 & 4.94 & 0.004 \\
\hline$L^{2}$ & -0.3444 & 0.0597 & -5.77 & 0.002 \\
\hline$L D$ & 0.0925 & 0.0706 & 1.31 & 0.247 \\
\hline$D^{2}$ & -0.5732 & 0.0597 & -9.61 & 0.000 \\
\hline
\end{tabular}

Table 3. Analysis of variance.

\begin{tabular}{|l|c|c|c|c|c|}
\hline Source & $\begin{array}{c}\text { Degrees of } \\
\text { freedom }\end{array}$ & SS & MS & $\boldsymbol{F}$ & $\boldsymbol{P}$ \\
\hline Regression & 5 & 2.6110 & 0.5222 & 26.17 & 0.001 \\
\hline Error & 5 & 0.0997 & 0.0199 & & \\
\hline Total & 10 & 2.7107 & & & \\
\hline
\end{tabular}

$\mathrm{SS}=$ sum of squares; $\mathrm{MS}=$ mean square; $\mathrm{F}$ and $\mathrm{P}=$ statistical parameters which indicate how far away a result is from the hypothesis

as evidenced from the $p$-value (0.001) obtained. The model showed a high determination coefficient, which explains $96 \%$ of the variability in the response.

According to the contour graphic (Fig. 4), monopropellant microthrusters using the new bulk mixed oxide catalyst for rocket grade stabilized $\mathrm{H}_{2} \mathrm{O}_{2}$ decomposition yield optimum thrust when the catalytic bed has length from 29 to $33 \mathrm{~mm}$ and diameter from 15 to $17 \mathrm{~mm}$. Thrust, specific impulse and characteristic velocity curves obtained within these optimized dimensions ( $D=15 \mathrm{~mm}$ and $L=30 \mathrm{~mm}$ ), with chamber pressure $P_{c} \sim 5.3$ bar, are shown, respectively, in Figs. 5, 6 and 7.

The propellant mass flow rate $(\dot{\mathrm{m}})$ was determined from injection pressure $(\Delta P)$ considering the following polynomial equation, obtained from a regression of 16 experimental data (up to 9 bar) using water injection, prior to fire tests in the thrust balance:

$$
\dot{m}=0.009 \Delta P^{2}+0.613 \Delta P+0.766 ; R^{2}=0.999
$$

The thruster specific impulse (Isp) was then determined by:

$$
I s p=\frac{F}{\dot{m} g_{o}}
$$

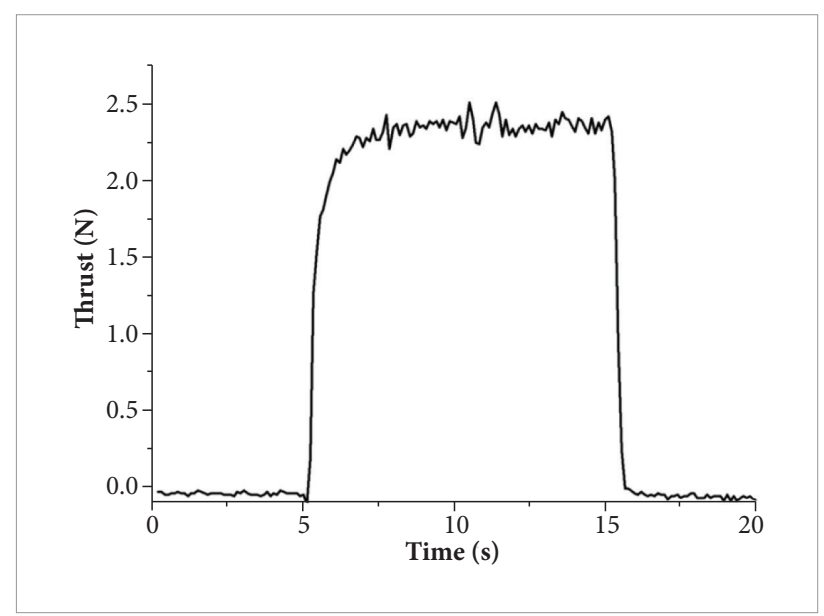

Figure 5. Thrust (N) obtained with CoMnAl based catalyst: $D=15 \mathrm{~mm}$ and $L=30 \mathrm{~mm}\left(P_{\mathrm{c}} \sim 5.3 \mathrm{bar}\right)$.

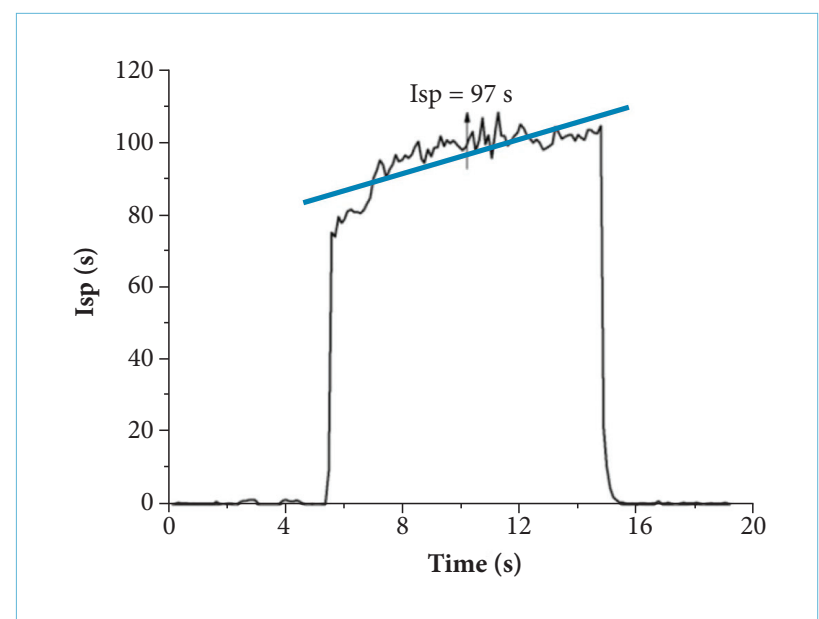

Figure 6. Specific impulse obtained with CoMnAl based catalyst: $D=15 \mathrm{~mm}$ and $L=30 \mathrm{~mm}\left(P_{\mathrm{c}} \sim 5.3 \mathrm{bar}\right)$.

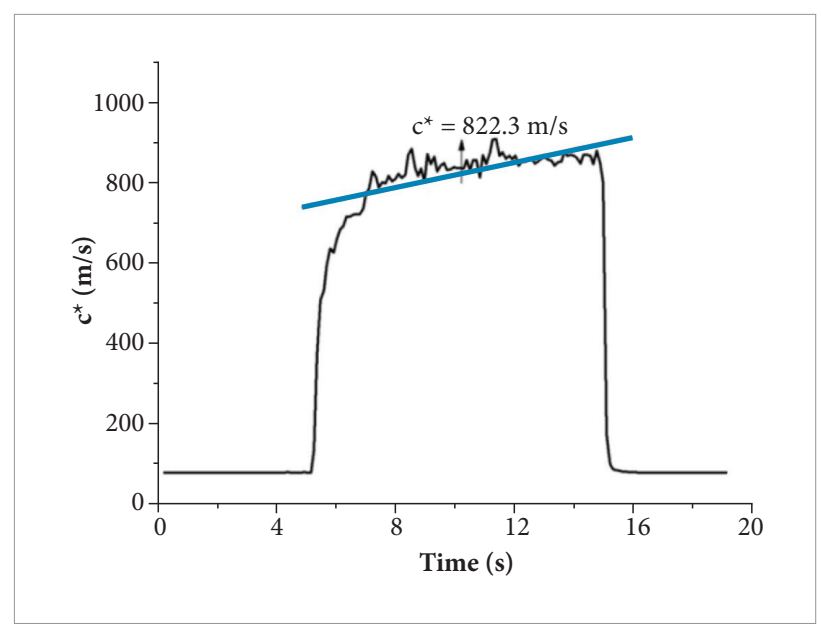

Figure 7. Characteristic velocity obtained with CoMnAl based catalyst: $D=15 \mathrm{~mm}$ and $L=30 \mathrm{~mm}\left(P_{\mathrm{c}} \sim 5.3 \mathrm{bar}\right)$. 
where $F$ is the measured thrust and $g_{0}=9.8065 \mathrm{~m} / \mathrm{s}^{2}$ is the standard gravity acceleration (Sutton and Biblarz, 2000). An average experimental specific impulse of $97 \mathrm{~s}$ was obtained (Fig. 6). This value is close to $106 \mathrm{~s}$, the value calculated with the NASA CEA code (1996). Therefore, the experimental result is satisfactory, since various losses occur in the process.

The experimental characteristic velocity was obtained by:

$c^{*}=\frac{A_{t} P_{c}}{\dot{m}}$

where $P_{\mathrm{c}}$ is the measured chamber pressure and $A_{\mathrm{t}}=3.6 \mathrm{~mm}^{2}$ is the nozzle throat area.

Since the characteristic velocity is a function only of temperature and gas properties in the combustion chamber, one can use this parameter to examine the chamber independently of the nozzle. The theoretical value obtained was $940 \mathrm{~m} / \mathrm{s}$ and the experimental average value was $822.3 \mathrm{~m} / \mathrm{s}$ (Fig. 7), corresponding to a characteristic velocity efficiency of $87 \%$, which indicates incomplete catalytic decomposition. However, this can be considered a high $c^{\star}$ efficiency for hydrogen peroxide decomposition, when compared to results of Pasini et al. (2007) as depicted on Table 4.

Finally, a continuous firing of 30 seconds (Fig. 8) and a sequence of 12 pulsed firings of 5 seconds, at intervals of 5 seconds (Fig. 9), were performed to check the stability of the CoMnAl catalyst, both tests adjusting $P_{\mathrm{c}} \sim 5$ bar. There was no evidence of catalyst deactivation with respect to time, despite the use of stabilized hydrogen peroxide. No fragmentation of the catalyst grains was observed after tests. Pressure drops in the catalytic bed were about 0.5 bar and approximately constant (Fig. 10). However, long duration and shorter pulse tests, at various mass flow rates and pressures, will still be performed to evaluate thruster performance on a broader operational range.

Table 4. Comparison of $C^{\star}$ efficiencies.

\begin{tabular}{|c|c|}
\hline$C^{*}$ efficiency $[\%]$ & Catalyst \\
\hline 58 & Platinum supported in alumina \\
\hline 80 & Silver screen \\
\hline 87 & Present work \\
\hline
\end{tabular}

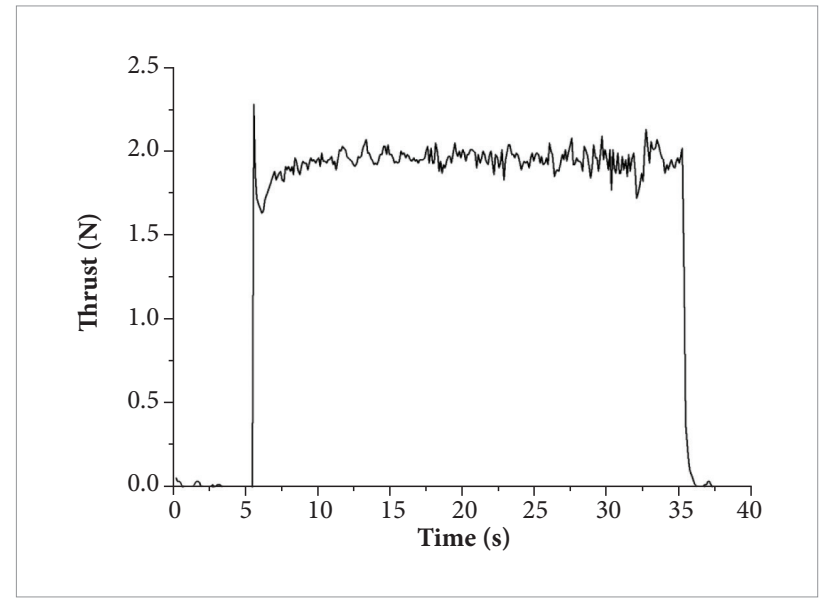

Figure 8. Thrust curve obtained during continuous 30-s test with CoMnAl based catalyst $\left(P_{\mathrm{c}} \sim 5\right.$ bar).

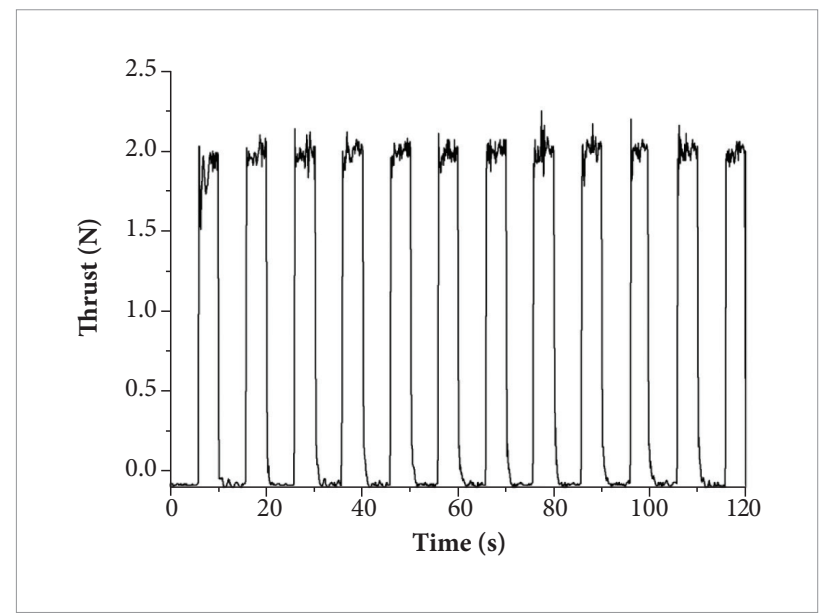

Figure 9. Thrust curve during pulsed test, $5 \mathrm{~s}$ on $/ 5 \mathrm{~s}$ off, with CoMnAl based catalyst $\left(P_{\mathrm{c}} \sim 5\right.$ bar $)$.

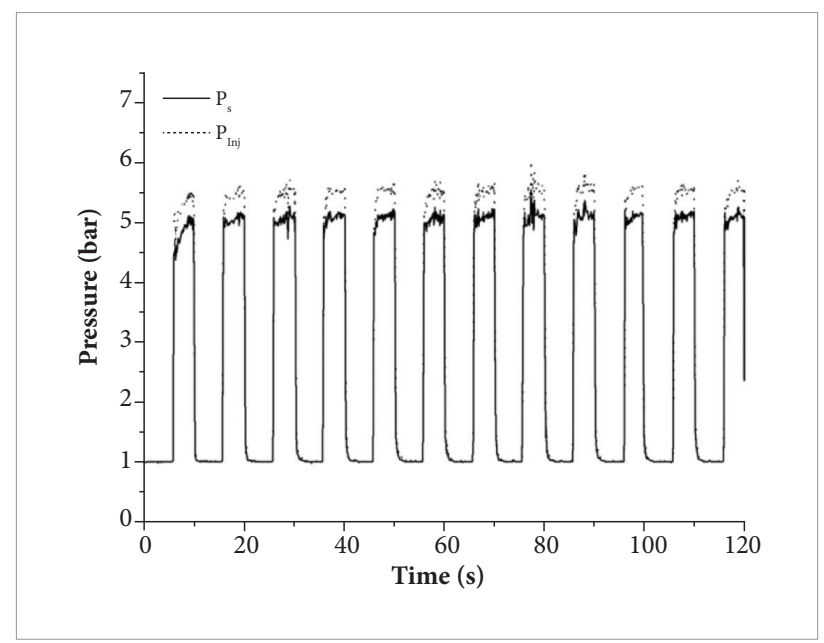

Figure 10. Pressure curves obtained during a pulse test, 5 s on/5s off, with CoMnAl based catalyst. 


\section{CONCLUSIONS}

Bulk catalysts based on mixed oxides, containing Co, Mn and $\mathrm{Al}$, were prepared and showed capable of promoting various cold starts in the decomposition reaction of $\mathrm{H}_{2} \mathrm{O}_{2}$ in a $2 \mathrm{~N}$ microthruster. The catalyst showed high catalytic activity, despite its low specific surface. The catalytic bed sizes, for rocket grade $\mathrm{H}_{2} \mathrm{O}_{2}$ decomposition using the new CoMnAl based catalyst, were optimized to obtain maximum thrust in a modular microthruster. A design of experiments methodology allowed the determination of the optimum dimensions of the catalytic bed: length from 29 to $33 \mathrm{~mm}$ and diameter from 15 to $17 \mathrm{~mm}$. For an optimized catalytic bed, the measured specific impulse was 97s, and the characteristic velocity efficiency was about $87 \%$. Additional tests will be performed to evaluate thruster performance in a broader operational range.

\section{ACKNOWLEDGMENTS}

The authors acknowledge the Fundação de Amparo à Pesquisa do Estado de São Paulo, the Agência Espacial Brasileira and the Conselho Nacional de Desenvolvimento Científico e Tecnológico for supporting this research.

\section{REFERENCES}

Barros-Neto, B., Scarminio, I.S. and Bruns, R.E, 1995, Planejamento e Otimização de Experimentos, UNICAMP, Campinas, SP, Brazil (in Portuguese).

Goldstein, J.R. and Tseung, A.C.C., 1974, "The kinetics of hydrogen peroxide decomposition catalyzed by cobalt-iron oxides". Journal of Catalysis, Vol. 32, No. 3, pp. 452-465.

Hasan, M.A., Zaki., M.I., Pasupulety, L. and Kumari, K., 1999, "Promotion of the hydrogen peroxide decomposition activity of manganese oxide catalysts". Applied Catalysis A, Vol. 181, No. 1, pp. 171-179.

Kappenstein, C., Pirault-Roy, L., Guérin, M., Wahdan, T., Ali, A.A., Al-Sagheer, F.A. and Zaki., M.I., 2002, "Monopropellant decomposition catalysts: thermal decomposition and reduction of permanganates as models for the preparation of supported $\mathrm{MnO}_{\mathrm{x}}$ catalysts". Applied Catalysis A, Vol. 234, No. 1, pp. 145-153.

McBride, B.J. and Gordon, S., 1996, "Computer program for calculation of complex chemical equilibrium compositions and applications, II-Users manual and program description", NASA-RP-1311.
Pasini, A., Torre, L., Romeo, L., Cervone, A., d'Agostino, L., Musker, A.J. and Saccoccia, G., 2007, "Experimental characterization of a $5 \mathrm{~N}$ hydrogen peroxide monopropellant thruster prototype", AIAA 2007-5465, 43 ${ }^{\text {rd }}$ AIAA/ASME/SAE/ASEE Joint Propulsion Conference \& Exhibit, Cincinnati, OH, USA.

Rusek, J.J., 1996, "New decomposition catalysts and characterization techniques for rocket grade hydrogen peroxide". Journal of Propulsion and Power, Vol. 12, No. 3, pp. 574-579.

Sutton, G.P. and Biblarz, 0., 2000, Rocket Propulsion Elements, 7a ed., John Wiley \& Sons.

Vaccari, A., 1998, "Preparation and catalytic properties of cationic and anionic clays”. Catalysis Today, Vol. 41, No. 1-3, pp. 53-71.

Wernimont, E. and Ventura, M., 2009, "Low temperature operation of hydrogen peroxide gas generators: verification testing and possible applications", AIAA Paper 09-4617. 